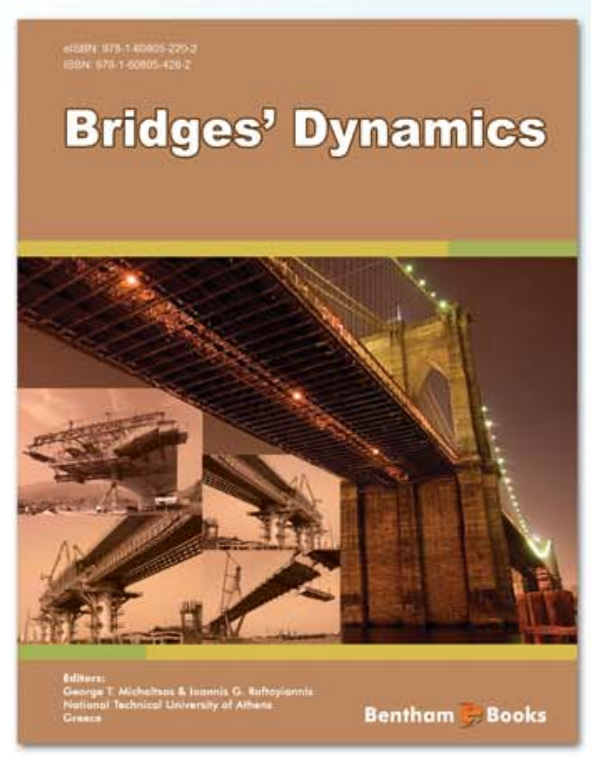

\section{Editors: \\ George T. Michaltso \\ Greece}

\section{loannis G. Raftoyiannis}

Greece

\title{
Bridges’ Dynamics
}

\section{Wuw.henthamscience.com/ehooks/978160805220-2}

\section{About the ebook}

This e-book explains the theory behind engineering aspects such as 1) dynamic loadings, 2) mathematical concepts 3) moving loads, 4) bridge support mechanics, 5) Static systems under dynamic loading 6) aero-elasticity, 7) space problems and 8) absorb systems (equations governing the behavior of the bridge-absorber system). The e-book is a useful introductory textbook for civil engineers interested in the theory of bridge structures.

\section{Contents}

Distressing - Loading - Modelling of Vehicles

Principles of Dynamic Analysis

The Problem of Moving Loads

Motion of Supports

Structural Analysis of Bridges

Aeroelasticity

For Sales and Advertising Inquiries: Contact: marketing@benthamscience.org 